\title{
Effectiveness of Mindfulness-Based Cognitive Therapy on Quality of Life and Body Image in Women With Breast Cancer Undergoing Mastectomy
}

\author{
Zahra Sharbaf Olyaie ${ }^{1}$, Hassan Toozandehjani ${ }^{1}$, Mohsen Dehghani Neyshabouri ${ }^{2 *}$ \\ 1. Department of General Psychology, Faculty of Humanities, Neyshabur Branch, Islamic Azad University, Neyshabur, Iran \\ 2. Department of Clinical Psychology, University of Social Welfare and Rehabilitation Sciences, Tehran, Iran.
}

Chat on: Sharbaf Olyaie Z, Toozandehjani H, Dehghani Neyshabouri M. Effectiveness of Mindfulness-Based Cognitive Therapy on Quality of Life and Body Image in Women With Breast Cancer Undergoing Mastectomy. 2016; 14(3):139-150. https://doi.org/10.18869/nrip.irj.14.3.139

dof: $:$ https://doi.org/10.18869/nrip.irj.14.3.139

Article info:

Received: 22 Mar. 2016

Accepted: 05 Aug. 2016

\section{Keywords:}

Mindfulness-based cognitive therapy, Body image, Quality of life

\section{A B STRACT}

Objectives: The present research has been carried out to investigate the effectiveness of group mindfulness-based cognitive therapy on modification of body image and quality of life in women with breast cancer undergoing mastectomy.

Materials: This research is a quasi-experimental study (pretest-posttest with control). In this clinical trial, 50 voluntary patients who had undergone mastectomy in 2013 and 2014 were screened among the patients admitted to Omid Hospital and Reza Treatment Center in Mashhad and were randomly divided into experimental group $(n=25)$ and control group $(n=25)$. First, both groups were pretested. Then, the experimental group received group mindfulness-based cognitive therapy treatments during eight sessions of 120 minutes (one session per week), but the control group received no treatment. At the end of treatment, both groups received the post-test. Data collection tools included standard questionnaires EROTIC QLQ-Br 23.V.3 and the quality of life questionnaire (SF-36). The data were analyzed based on covariance analysis using SPSS software (Version 20).

Results: Comparison of the mean scores of quality of life and body image showed a significant difference between the control and experimental groups after receiving the treatment $(\mathrm{P}<0.01)$. In other words, mindfulness-based cognitive therapy was effective on the quality of life and modification of body image in patients.

Discussion: Group mindfulness-based cognitive therapy can be considered as an effective and efficient approach to the quality of life and modification of body image in women with breast cancer who have undergone mastectomy.

\section{Introduction}

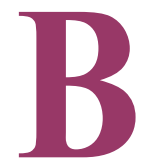

reast cancer is the most common cancer worldwide and the most common cause of cancer death toll in Iranian women
[52]. In Iran, the age of onset of this disease is about 10 years younger than worldwide, and the peak age is 40-50 years. In many cases, the patients complain of advanced stages of the disease due to lack of awareness of the symptoms [46]. Therefore, although the prevalence

* Corresponding Author:

Mohsen Dehghani Neyshabouri, PhD Candidate

Address: Department of Clinical Psychology, University of Social Welfare and Rehabilitation Sciences, Tehran, Iran.

Tel: +98 (935) 9409582

E-mail: dehghani.mohsen66@gmail.com 
of this disease in Iran is about one-fifth of that in the Western countries, its death toll is unfortunately much more [24]. The incidence of breast cancer in men is 200 times fewer than women [1].

From the medical perspective, surgery or mastectomy is the preferred treatment for the removal of malignancies such as breast cancer. Surgery alone is often quite effective, but in advanced stages of tissue development, surgery might be used with other treatment approaches such as radiotherapy or chemotherapy. Research has shown that it is not necessary to remove the whole breast in many cases; instead, local surgery might be effective in removing the tumor [33].

The removal of one or both breasts is considered as the destruction of the part of the body that symbolizes gender, femininity, and motherhood dimensions [25]. High level of stress has significant negative effects on women's selfconfidence and ultimately adversely affects their household performance and marital role and lowers the quality of life [27]. Breast cancer and its treatment methods (such as mastectomy) cause physical and social problems and mental disorders (especially, mood disorder, fear, and concern about the mental image of body and reduced quality of life) [14].

Humans have physiological, mental, and social dimensions that are mutually interacting. Any alteration in a dimension affects the other dimensions; in other words, if the mental health improves, the physical health also improves [31]. On the other hand, mind and body are completely connected to each other, and thus, changes in the body will affect the emotional and intellectual health and quality of life [3]. Human beings live their body every moment from birth to death because the body and physical appearance are the most visible parts, the most constitutive elements of existence and one of the most important aspects of human identity $[3,31]$.

According to international standards, health does not only include physical aspects. The World Health Organization (WHO) has defined health as "a state in which the individual is quite healthy mentally, emotionally, and socially and no sign of illness or affliction is seen in him." Therefore, not only the traditional health indicators such as the rate of mortality and morbidity but also the individuals' perception of quality of life should be considered when assessing health [12].

Quality of life and the individuals' assessment of their quality of life have become very valuable. According to some researchers, the individuals' pleasure of their lives and their satisfaction with their being alive are the most important aspects to enjoy a happy life and good physical and psychological health [29].

Quality of life is the best criterion for measuring the individual's ability to cope with the challenges of the real world successfully. In different general and specific sources, various definitions of quality of life have been offered that ranges from "life satisfaction" to "individual's functional ability." The concepts used in the perception of quality of life include satisfaction and dissatisfaction, life conditions, happiness, unhappiness, life experiences, and factors such as comfort, functional status, socioeconomic situation, independence, and environmental conditions [11].

Philips (2006) has introduced two structures for quality of life. The first and foremost structure is the subjective approach that includes the individual's perception of quality of life and the individual's assessment of important aspects of quality including the relationship with family and friends, personal health, health of family and friends, and living costs and standards. The second structure is the subjective approach towards the quality of life including income and living conditions, which involve the social factors affecting the quality of life.

Some of these factors include security, social-economic status, environment, health, government and political system, moral and civil norms, education, culture and recreation, social environment, family life and human services, public transportation and infrastructures, and employment. In subjective approach, all the social components are important and cannot be ignored.

Women with breast cancer are the largest survival group after the incurrence of cancer, but there is limited information about their quality of life [22]. Quality of life is a multidimensional concept that is influenced by body position, mental image of body, functional status, mental stress, side effects of treatment, social communication, and individual's satisfaction with medical care [4].

Characteristics of cancer such as the type and stage of cancer, early diagnosis, patients' acceptance of their disease, cancer pain, mental stress, and caregivers' behavior affect the quality of life of cancer patients [23].

Grant and Ferrel (1994) have defined the quality of life of cancer patients in four dimensions: 1. Physical wellbeing, 2. Psychical and mental well-being, 3 [47]. Social well-being, and 4. Spiritual well-being. Each of the dimensions includes general issues or topics for cancer patients and particular or specific topics for different types of cancer patients [26]. 
Dow (1999) states that breast surgery can affect the weight, mental, and social dimensions of the patient. After the operation, the patient often suffers from pain, disability, fatigue, changes in mental image, mood disorders (depression and anxiety) and decrease in self-confidence [13]. Moreover, the increase of dependence on others, changes in work pattern, and changes in social and family communication can influence the patient's hope and quality of life. There is a kind of relationship between demographic variables such as age, marital status, income, education level, employment status, and the quality of life.

Sammarco (2001) reported that in younger women, the fear of cancer recurrence, sexual and reproductive dysfunction, premature menopause, menstrual disorder, and the effects of cancer and its treatment on the family members are among the issues that affect their quality of life [34]. However, he also reported that the quality of life in elderly women is affected by physical function, underlying chronic illness, loss of the partner and living alone, and insufficient financial resources.

Pain can affect the quality of life of patient with breast cancer. Studies show that one of the most common physical problems mentioned by the patients with cancer is pain. Pain after mastectomy occurs in $5 \%$ to $10 \%$ of women, and it seems that the pain is more serious in women after the removal of lymph nodes and might last for months or even years [14].

Uzun (2004) stated that patients with breast cancer suffer from many problems due to trauma resulting from the removal of breast and its effect on the quality of life. He also reported that the patients with modified radical mastectomy have a lower quality of life than the patients with lumpectomy and simple mastectomy [42].

In a research conducted by Fasihi Harandi et al. (2011) to explain the quality of life of women with breast cancer in a qualitative manner, the most important factors affecting the quality of life in terms of physical dimension, pain and swelling in hands, fatigue, and loss of ability to do daily activities were reported [16]. The results of the research showed that in emotional-social dimension, disorder in the mental image of body, lack of mental-social supports, lack of or inadequate insurance coverage, expensive chemotherapy drugs and other treatment costs were some of the most important factors influencing the quality of life of the patients and their families.

Another important psychological concept that often concerns men and women is the mental image of body. The mental image of body is a subjective concept and the per- sonal relationship between the individual and his/her body. It particularly includes beliefs, perceptions, thoughts, feelings, and actions that are related to the physical appearance of human. This image changes due to the events, illnesses, alteration in the appearance, and dysfunction of body organs. Body image is rooted in scientific psychology and is a proactive and cognitive behavioral approach [7]. Mental image of body is a subjective issue that the person feels every moment and is based on the individual's current and past perception of his/her own body [31].

The problems of mental image of body and negative physical image are one of the most profound psychological consequences of cancer treatments that affect the patients in different situations. In women who have undergone breast surgery, the concerns range from the ulcers to the reduction of sexual attraction and restriction on the use of certain types of dress. In a survey of women who underwent breast conserving surgery, $25 \%$ of them had serious problems of mental image of the body [32].

Rowland and Holland (1987) stated that mastectomy causes a negative mental image of body and reduces selfconfidence and thus increases the patients' anxiety and depression and reduces their quality of life [48]. Kissan et al. (1998) showed that breast conserving surgery is followed by a better mental image of body [18].

In order to compare sexual dysfunction and mental image of body in patients with breast cancer and healthy women, Bakht and Najafi (2010) selected a sample of 20 subjects for both groups. The results showed that there was no significant difference between the overall sexual performances, but there was a significant difference between all subscales of mental image of body except the body weight [6].

Weitzner et al. (1997) and Shimozuma et al. (1999) have concluded that in women who have undergone mastectomy, there is a relationship between mood and quality of life due to the fact that the disorder in mental image of body after mastectomy causes persistent stress and anxiety in patients with breast cancer and provides the ground for the mood changes $[45,48]$.

In this regard, the concerns on the effect of surgical treatment of breast cancer, particularly mastectomy, on quality of life are increasing in patients. The results show that there is a significant inverse correlation between the scores of mood and quality of life in women undergoing mastectomy [14].

One of the recent approaches towards treating stress and anxiety caused by environmental factors is the Mindfulness-Based Cognitive Therapy (MBCT). In this therapy, 
patients learn how to establish relationships differently with their negative thoughts and feelings and how to concentrate on changing the contents of their beliefs and ideas. They also learn how to change their automatic thoughts, habits, mental rumination, and negative thoughts and feelings, and to be aware of them and see their thoughts and feelings in a broader perspective [46].

Mindfulness is a therapeutic technique that is a combination of relaxation and a unique cognitive component [51]. MBCT teaches patients how to convert ruminative, habitual, and automatic patterns of mind immediately after recognition into thoughtful and deliberate patterns of mind, so that negative thoughts and feelings in a broader perspective can be recognized as easily passing events in mind. The main objective of MBCT therapeutic approach is to release patients from the tendency to react automatically to thoughts, feelings, and events and to return their attention to normal subjects (such as breathing and physical sensations) in the present moment. The participants are taught the direct empirical consciousness along with nonjudgmental acceptance attitude towards the events [39].

One of the destructive consequences that require mindfulness intervention is demoralization. In such people, isolation from community is not due to lack of interest but because they are not satisfied with the type of communication with the community. In addition, they have limited and narrow vision of future, and they usually have no specific real plans for their progress and future goals [43]

Hoffman et al. (2012) did research on 290 women with breast cancer after surgery, chemotherapy, and radiotherapy. They showed that eight sessions of cognitive therapy based on stress reduction in subjects can improve the quality of life depending on endocrine in women with breast cancer at stage 0 to 3 [49].

The results of the research conducted by Foley et al. (2010) showed that MBCT can significantly improve all aspects of life such as the quality of life in patients with cancer who receive the treatment compared with the patients without the treatment [10].

In a study carried out by Godfrin et al. (2010) on 106 depressed patients who had recovered from a history of at least three periods of persistent depression, the quality of life improvement was observed in the group that underwent MBCT [21].

Brotto et al. (2008) showed that mindfulness-based psychological invention would amazingly improve the quality of life in women with genital cancer [5]. Januseka et al. (2008) showed that mindfulness-based stress reduction program in women with newly diagnosed breast cancer (10 days after surgery and before chemotherapy) could improve the quality of life and effective compliance and better performance of immune system [50].

In a study carried out by Stafford et al. (2006) on 115 women with breast and genital cancer at the Association of Health Hospital in Australia, MBCT resulted in significant improvement in depression, anxiety, stress, and quality of life in patients [44]. In a quasi-experimental study by Norouzi et al. (2012) on 20 women with Alzheimer's disease in two control $(n=10)$ and experimental $(n=10)$ groups, the results showed that $\mathrm{MBCT}$ ( 8 sessions of two hours) in the experimental group (compared with the control group that received no treatment) significantly improved the quality of life and decreased depression, and the treatment results continued within the two-month follow-up [35].

Kaviani et al. used a quasi-experimental test-retest method for two experimental and control groups in order to investigate the effect of MBCT on the improvement of quality of life in depressed non-patients. The experimental group received eight sessions of MBCT training weekly for 90 to 120 minutes. The control group received no medical training. The results showed that MBCT can improve quality of life and reduce depression [19].

Therefore, it is important to focus consciously on physical feelings, so as to avoid rumination. Consequently, it will be tried to solve problems through mental concepts and the attention will be drawn towards direct experience of opinions (just the events that are in the realm of consciousness) and thus, this part of negative cycle of thoughts will be controlled by the individual [46].

Given that the therapist is responsible for helping individuals with breast cancer to overcome the conditions that restrict and reduce the quality of life, one of the main objectives of treatment of such individuals is to improve their quality of life. Therefore, the present study was designed to determine the effect of group MBCT on the mental image of body and quality of life in women with breast cancer (who have undergone mastectomy).

\section{Methods}

This study is a randomized clinical trial carried out on 50 women with breast cancer who have undergone mastectomy. The research population includes all single and married women with breast cancer who were referred to the Oncology Department of Omid Hospital Na d Reza Health Center in Mashhad (during the first three months 
in 2013-2014). The patients were screened according to the forms that contained their personal information and medical information (and that were submitted to a few of oncologists). After obtaining the subjects' consent, a sample of 50 subjects was selected through convenient and voluntary sampling and randomly divided into experimental group $(n=25)$ and control group $(n=25)$.

The research inclusion criteria consisted of consent to participate in the research, Iranian nationality, and age younger than 70 years. The exclusion criteria consisted of the history of chronic diseases (cardiovascular, renal, liver, asthma, thyroid disorders, organic brain disorders), mental disorders, other cancers, use of psychotropic drugs (analgesics, antiemetic, steroids) during one week before the study, presence of stressful events (divorce, death of a close relative, job loss, major change in life) during the past six months, and drug addiction. The minimum education degree of the participants was the primary school.

\section{Data collection tools}

\section{Patient Characteristics Questionnaire}

In this research, at first a form containing personal information and information about the disease was prepared and delivered to the patients.

\section{Quality of Life Questionnaire (SF36)}

The purpose of the questionnaire is to assess the subject's physical and mental health by combining the scores of eight domains of health. The 36-item questionnaire examines 8 health concepts (general health perception, physical dimension, role limitation due to physical reasons, role limitation due to emotional reasons, bodily pain, social functioning, fatigue or vitality, mental or emotional health). The questions are scored from 0 to 100 in the SF36 questionnaire. In each question, 100 score indicates the best quality of life and 0 represents the lowest quality of life. The questionnaire was examined in the United Kingdom by Brazier et al. (1992) to determine its reliability. The results showed that the reliability of SF36 was $85 \%$ based on the Cronbach's alpha [52].

The quality of life questionnaire SF36 has been used internationally, and in Iran, it was used by the professors and students at the Tarbiat Modarres University to investigate the quality of life in patients with cancer [52].

\section{EROTIC QOL-Br 23 Questionnaire}

It is a cancer-specific questionnaire and measures the quality of life in patients with breast cancer. It contains function scales (body image, sexual performance, and sexual pleasure) and symptom scales (arm symptoms, breast symptoms, side effects of treatment and concern about hair loss). In this research, the functional scale of body image was examined. It should be noted that this is the complementary questionnaire following the EROTIC QLQ-C3 questionnaire, which includes functional and symptom scales (sleep disturbance, nausea, vomiting, etc). The questionnaire was normalized in Iran by Montazeri et al. (2000) [30].

In both questionnaires, the Cronbach's alpha coefficient is more than 0.70 , which indicates their good reliability. The questionnaire grading is based on 4-point Likert scale (ranging from 1 to 4 as no way, little, much, too much). The sum of scales in both questionnaires is converted to 0 to 100 and interpreted, so that higher scores in functional scales indicate better levels of performance.

\section{Procedures}

In this study, 50 voluntary patients who had undergone mastectomy in 2013 and 2014 were screened among the patients admitted to Omid Hospital and Reza Treatment Center in Mashhad and were randomly divided into experimental group $(n=25)$ and control group $(n=25)$. First, both groups were pretested. Then, the experimental group received group mindfulness-based cognitive therapy treatments during eight sessions of 120 minutes (one session per week), but the control group received no treatment. At the end of treatment, both groups received the post-test. Data collection tools included standard questionnaires EROTIC QLQ-Br 23.V.3 and the quality of life questionnaire (SF-36). The data were analyzed based on covariance analysis using SPSS software (Version 20).

\section{Results}

In this research, the scores of mental image of body and quality of life were collected through appropriate questionnaires. The descriptive data of the parameters for the control group are shown in Tables 1,2. With regard to the incomplete questionnaires, there is complete data for all the variables for the control group. In other words, no data is lost.

The descriptive data of the experimental group including central tendency and distribution are presented in Tables 3 and 4. The main central tendency criteria are the means, and the most important criterion of the distribution is the standard deviations, which are affected by remote variables less than the other parameters.

The number of subjects in the experimental group, like control group, is $25(\mathrm{n}=25)$; therefore, no data is lost in the 
Table 1. Descriptive data related to the control group for mental image of body and quality of life in women with breast cancer undergoing mastectomy.

\begin{tabular}{lccccc}
\hline \multicolumn{2}{c}{ Control Group } & Number & Extent of Change & Mean & SD \\
\hline \multirow{2}{*}{ Body image } & Pretest & 25 & 62.50 & 74 & 18.45956 \\
& Posttest & 25 & 68.75 & 86.2500 & 16.73164 \\
\multirow{2}{*}{ Quality of life } & Pretest & 25 & 54.69 & 46.4508 & 14.78089 \\
& Posttest & 25 & 40.85 & 32.8884 & 11.20649 \\
\hline
\end{tabular}

Iranian Rehabilitation Journa

the feeling of more willpower and control in life [43]. In the states of "mindfulness" information broadcast twists from the defective mutual cycles towards immediate and current experience. In fact, mindfulness training teaches the individuals how to release the habit skills "located in central engine" from the rigid state and provide the conditions for change by directing information processing resources towards the neural targets of attention such as breathing or feeling the moments. Body exercising will transform the model schema [20].

The findings on the effect of MBCT on the increase of quality of life are consistent with the findings of Kaviani et al. (2008), Noroozi et al. (2012), Crane 2008), Foley et al. (2010), Godfrin et al. (2010), Brotto et al. (2008), Witek-Janusek et al. (2008), and Stafford et al. (2006) $[5,9,15,20,21,35,44]$. The results of the present study

Table 2. Descriptive data related to the subscales of quality of life in the control group for women with breast cancer undergoing mastectomy.

\begin{tabular}{|c|c|c|c|c|c|}
\hline Control Group & & Number & Extent of Change & Mean & SD \\
\hline \multirow{2}{*}{ Physical dimension } & Pretest & 25 & 70 & 54.8000 & 19.92068 \\
\hline & Posttest & 25 & 65 & 39.2000 & 15.92168 \\
\hline \multirow{2}{*}{ Physical role } & Pretest & 25 & 75 & 24 & 23.36308 \\
\hline & Posttest & 25 & 50 & 9 & 14.21650 \\
\hline \multirow{2}{*}{ Physical pain } & Pretest & 25 & 77.50 & 64.9000 & 21.04658 \\
\hline & Posttest & 25 & 77.50 & 53.1000 & 18.58651 \\
\hline \multirow{2}{*}{ General health } & Pretest & 25 & 60 & 41.2000 & 17.63519 \\
\hline & Posttest & 25 & 55 & 30 & 14.57738 \\
\hline \multirow{2}{*}{$\begin{array}{l}\text { Exhaustion and happi- } \\
\text { ness }\end{array}$} & Pretest & 25 & 70 & 47.8000 & 16.65083 \\
\hline & Posttest & 25 & 55 & 37 & 10.80123 \\
\hline \multirow{2}{*}{ Social performance } & Pretest & 25 & 75 & 59 & 19.60547 \\
\hline & Posttest & 25 & 37.50 & 42 & 14.37953 \\
\hline \multirow{2}{*}{ Emotional health } & Pretest & 25 & 80 & 50.5600 & 19.76154 \\
\hline & Posttest & 25 & 60 & 40.8000 & 16.61325 \\
\hline \multirow{2}{*}{ Mental health } & Pretest & 25 & 100 & 29.3333 & 35.11888 \\
\hline & Posttest & 25 & 66.67 & 12 & 21.25681 \\
\hline
\end{tabular}


Table 3. Descriptive data related to the experimental group for mental image of body and quality of life in women with breast cancer undergoing mastectomy.

\begin{tabular}{lccccc}
\hline \multicolumn{2}{c}{ Experimental Group } & Number & Extent of Change & Mean & SD \\
\hline \multirow{2}{*}{ Body image } & Pretest & 25 & 56.25 & 67.5000 & 15.09518 \\
& Posttest & 25 & 12.50 & 31.7500 & 5.37755 \\
\multirow{2}{*}{ Quality of life } & Pretest & 25 & 47.19 & 39.1800 & 13.43643 \\
& Posttest & 25 & 33.44 & 81.8940 & 8.73326 \\
\hline
\end{tabular}

experimental group. After descriptive analysis of the data and before testing the research hypotheses, it is necessary to examine the normality of the observations to determine an appropriate method for testing the hypotheses. The normality of each group was examined through KolmogorovSmirnov test. The results are separately displayed in Table 5 for the variables in both experimental and control groups. The results showed that the assumption of normality of observations for the mentioned items is accepted $(\mathrm{P}>0.05)$.

The results of Table 5 show that the significance level in all cases is more than 0.05 . Therefore, the null hypothesis in Kolmogorov-Smirnov test on the normality of observations for the mentioned items is accepted $(\mathrm{P}>0.05)$. With regard to the confirmation of the normality of the observations, the covariance analysis test can be used.

The results of Table 6 show that the computed F-statistic $(\mathrm{F}=30.863)$ is greater than its corresponding value in Fisher Table $(\mathrm{F}=3.93)$. Therefore, with $95 \%$ confidence, it is concluded that the compared means of quality of life in experimental and control groups and in the post-test stage are not consistent. According to the collected data and with regard to insignificant null hypothesis, the researcher's claim that "Mindfulness-based cognitive therapy affects the quality of life in women with breast cancer undergoing mastectomy" is confirmed $(\mathrm{P}<0.01)$.

The results of Table 7 show that the computed F-statistic $(\mathrm{F}=63.612)$ is greater than its corresponding value in Fisher's Table $(\mathrm{F}=3.93)$. Therefore, with 95\% confidence, it is concluded that the compared means of mental image of body in experimental and control groups and in post-test stage are not consistent. According to the collected data and with regard to insignificant null hypothesis, the researcher's claim that "Mindfulness-based cognitive therapy affects the modification of mental image of body in women with breast cancer undergoing mastectomy" is confirmed $(\mathrm{P}<0.05)$.

\section{Discussion}

As results showed, there was a significant difference between the control and experimental groups after receiving the treatment. In other words, mindfulness-based cognitive therapy was effective on increasing the quality of life and modification of body image in patients. So group mindfulness-based cognitive therapy can be considered as an effective and efficient approach to the quality of life and modification of body image in women with breast cancer who have undergone mastectomy.

Many cancer patients have mental problems resulting from changes in their relationships with their families and friends. In some cases, the patient avoids social relationships because the disease makes them feel ugly or embarrassed. This is more pronounced in women with breast cancer because they not only lose their hair and eyebrow but also the form of their bodies changes [33].

The removal of one or two breasts is often accompanied by emotional responses such as severe depression, grief, loss of control, personality change, anger, anxiety due to fear of death, and disability. This occurs in over $20 \%$ of the patients with cancer [8].

Chen et al. (2000) found that women who undergo breast conserving surgery have better quality of life than the women who have undergone mastectomy until three years after the surgery [25]. Supportive care and intervention are done for women with breast cancer in order to reduce the mental social effect of cancer and improve their quality of life. This point is necessary to be considered as a basic part of their treatment [28]. Moreover, our findings are also consistent with the findings of Uzun (2004), Shimozuma et al. (1999), Rowland and Holland (1987), and Weitzner et al. (1997) [42, 45, 48].

Through the treatment, the subjects are taught that the simple act of thought recognition in this method can release them from the distorted reality, develop insight, and create 
Table 4. Descriptive data related to the subscales of quality of life in the experimental group.

\begin{tabular}{|c|c|c|c|c|c|}
\hline Experimental Group & & Number & Extent of Change & Mean & SD \\
\hline \multirow{2}{*}{ Physical dimension } & Pretest & 25 & 60 & 51.6000 & 17.48333 \\
\hline & Posttest & 25 & 35 & 83.2000 & 9.66954 \\
\hline \multirow{2}{*}{ Physical role } & Pretest & 25 & 75 & 14 & 22.821777 \\
\hline & Posttest & 25 & 75 & 77 & 21.55420 \\
\hline \multirow{2}{*}{ Physical pain } & Pretest & 25 & 87.50 & 44.9000 & 22.87284 \\
\hline & Posttest & 25 & 65 & 72.4000 & 20.46949 \\
\hline \multirow{2}{*}{ General health } & Pretest & 25 & 70 & 43.2000 & 17.78810 \\
\hline & Posttest & 25 & 45 & 84.4000 & 10.34005 \\
\hline \multirow{2}{*}{ Exhaustion and happiness } & Pretest & 25 & 55 & 50.5000 & 14.50575 \\
\hline & Posttest & 25 & 30 & 88.5000 & 8.52936 \\
\hline \multirow{2}{*}{ Social performance } & Pretest & 25 & 62.5 & 38.2400 & 17.48511 \\
\hline & Posttest & 25 & 37.50 & 79.0400 & 12.97032 \\
\hline \multirow{2}{*}{ Emotional health } & Pretest & 25 & 56 & 38.2400 & 14.88086 \\
\hline & Posttest & 25 & 44 & 79.0400 & 10.01865 \\
\hline \multirow{2}{*}{ Mental Health } & Pretest & 25 & 100 & 31.9999 & 26.31722 \\
\hline & Posttest & 25 & 33.33 & 96 & 1105531 \\
\hline
\end{tabular}

Iranian Rehabilitation Journa

are als consistent with the results of the research on the effectiveness of MBCT on quality of life in patients with cancer. Women who have undergone mastectomy tolerate a lot of stress and anxiety for a longer duration due to disruption of mental image of body [38, 48].

In the research conducted by Ajirloo et al. (2012), the population included patients with breast cancer aged 30 to 60 years who had been refereed to Imam Hossein Hospital
(PBUH) in Tehran and received radiotherapy after mastectomy surgery. The members of both groups in pretest and posttest were evaluated based on Ellis Pope scale of mental image of body and colleagues and self-esteem. The experimental group received "group cognitive therapy treatment" in the form of 12 sessions of 90 minutes (twice a week). The results showed that the applied treatment affected the modification of mental image of body and increased the self-esteem in women who had undergone mastectomy [51].

Table 5. The results of Kolmogorov-Smirnov test for examining the normality of data in experimental and control groups.

\begin{tabular}{cccccc}
\hline & & \multicolumn{2}{c}{ Control } & \multicolumn{2}{c}{ Experiment } \\
\cline { 3 - 6 } & & $\begin{array}{c}\text { Kolmogorov-Smirnov } \\
\text { Test }\end{array}$ & Sig. & $\begin{array}{c}\text { Kolmogorov- } \\
\text { Smirnov Test }\end{array}$ & Sig. \\
\hline \multirow{2}{*}{ Body image } & Pretest & 0.864 & 0.445 & 0.660 & 0.777 \\
& Posttest & 0.627 & 9.826 & 0.452 & 0.920 \\
Quality of life & Pretest & 0.89 & 0.407 & 0.541 & 0.931 \\
& Posttest & 0.955 & 0.321 & 0.567 & 0.904 \\
\hline
\end{tabular}


Table 6. Covariance analysis results of the scores of quality of life questionnaire in women with breast cancer undergoing mastectomy.

\begin{tabular}{cccccc}
\hline & Sum of Square & df & Mean of Square & F & Sig. \\
\hline Constant & 91657.924 & 1 & 91657.924 & 259.853 & 0.000 \\
\hline Type of test (pretest-posttest) & 5311.349 & 1 & 91657.924 & 15.058 & 0.000 \\
\hline Group (control vs. experiment) & 10886.210 & 1 & 91657.924 & 30.863 & 0.000 \\
Error & 34214.210 & 97 & 352.730 & & \\
\hline Total & 50412.345 & 99 & & & \\
\hline
\end{tabular}

Iranian Rehabilitation Journa Table 7. Covariance analysis results of the scores of mental image of body questionnaire in women with breast cancer undergoing mastectomy.

\begin{tabular}{cccccc}
\hline & Sum of Square & df & Mean of Square & F & Sig. \\
\hline Constant & 250278.125 & 1 & 250278.125 & 684.582 & 0.000 \\
Type of test (pretest-posttest) & 3451.563 & 1 & 3451.563 & 9.441 & 0.003 \\
Group (control vs. experiment) & 23256.250 & 1 & 23256.250 & 63.612 & 0.000 \\
Error & 35462.500 & 97 & 365.593 & & \\
Total & 62170.313 & 99 & & & \\
\hline
\end{tabular}

Iranian Rehabilitation \ourna|

Fadaei et al. (2011) conducted a research to determine the effect of Ellis's rational-emotional therapy on the mean score of mental image of body in women who had undergone mastectomy. In this quasi-experimental study, they randomly selected 72 women who had undergone mastectomy and had been referred to Isfahan Center of Oncology and Radiotherapy. The experimental group $(n=32)$ participated in 6 sessions of treatment. The scores of mental image of body significantly decreased after the treatment in the experimental group, and there was a significant difference between two groups [17].

Abolghasemi and Jafari (2012) did a research on 40 subjects who were randomly selected from among the high school students with bulimia in Ardabil and divided into experimental group (dialectical behavior therapy which is in the third wave of behavioral therapy) and the waiting list. The experimental group received group dialectical behavior therapy during 12 sessions. In order to collect data, eating habits questionnaire, negative body image questionnaire, and self-efficacy inventory were used. According to the findings of the research, it can be said that dialectical behavior therapy has reduced bulimia, improved body image, and increased self-efficacy in patients under treatment [2].

\section{Conclusion}

According to the treatment approach, changing the patient's relationship with the pain caused by negative thoughts is essentially important because there is no possible way to relieve the patient of all his grieves. Neither cognitive therapy nor body checking can prevent the occurrence of unpleasant events in our daily life by themselves but their combination might provide a better vision to control such events. It could be said that one of the reasons of the effectiveness of group MBCT treatments is their training infrastructure because in such methods, it is emphasized to learn how to justify purposefully at every moment without judgment. This study has investigated the effect of MBCT on quality of life and modification of mental image of body in experimental and control groups. Since the quality of life and the mental image of body have improved in the experimental group, it can be said that this improvement reflects the impact of treatment on patient with cancer who have undergone mastectomy.

The researcher has faced some limitations during the research that might have influenced the quality of the research. Quality of life and body image are two subjective concepts that can be assessed by the individual himself. 
Therefore, the researcher's confidence in accuracy of the responses on behalf of the research units and also lack of strong history about breast cancer treatment in Iran are among the limitations of the research. Given the importance of psychological treatments in addition to specific treatments in patients with breast cancer, it is highly recommended to carry out other studies in this regard for more generalization.

\section{Acknowledgements}

The paper has not been extracted from a thesis and it has not had any financial supporters.

\section{Conflict of Interest}

The authors declared no Conflict of Interests.

\section{References}

[1] Anderson WF, Jatoi I, Tse J, Rosenberg PS. Male breast cancer: a population-based comparison with female breast cancer. Journal of Clinical Oncology. 2010; 28(2):232-39. doi: 10.1200/jco.2009.23.8162

[2] Abolghasemi A, Jafari E. [Effectivness of dialectical behavior therapy on body image and self-efficacy in with Bulimia Nervosa (Persian)]. Journal of Clinical Psychology. 2012; 4(2):2937.

[3] Atkinson A, Pudner R. Altered body image and the surgical patient. In: Pudner R, editor. Nursing the Surgical Patient. $3^{\text {rd }}$ ed. Edinburg: Elsevier Science Limited; 2005, p. 91-102.

[4] Braim RG. Assessing the quality of lite patients with cancer. Current Problem in Cancer. 2000; 24(2):58-86. doi: 10.1016/ s0147-0272(00)90009-6

[5] Brotto LA, Basson R, Luria M. Original research-psychology: A mindfulness-based group psychoeducational intervention targeting sexual arousal disorder in women. Journal of Sexual Medicine. 2008; 5(7):1646-659. doi: 10.1111/j.17436109.2008.00850.x

[6] Bakht S, Najafi S. Body image and sexual dysfunctions: comparison between breast cancer patients and healthy women. Procedia-Social and Behavioral Sciences. 2010; 5:1493-497. doi:10.1016/j.sbspro.2010.07.314

[7] Cash TF. The body image workbook: An 8-step program for learning to like your looks. Oakland: New Harbinger Publications, Inc.; 1997.

[8] Curtis A. (2006). Health Psychology [N. Mohammadi, Persian trans]. Tehran: Virayesh Press; 2006.

[9] Crane R. Mindfulness-based cognitive therapy: Distinctive features. New York: Taylor and Francis; 2008.
[10] Yazdi A, Bahmani B. [Effectiveness of cognitive-behavioral group intervention on improving self-esteem and body image in women with breast cancer after mastectomy (Persian)]. Journal of Rehabilitation Research. 2012; 13(4):72-83.

[11] Chambers M. Quality indicators for progress: A guide to community quality of life assessments. Jacksonville: Jacksonville Community Council, Inc.; 2004.

[12] Campos MG. Quality of life differences between firs year undergraduate financial aid and non-aid recipients [MA thesis]. Virginia: University of Virginia.

[13] Dow K. Breast Cancer [A. A. Akbari, Persian trans]. Tehran: Salamat Press; 2011.

[14] Fazel A, Tirgari B, Mokhber, Koshyar MM, Ismaili H. [Mastectomy Effects on mood and quality of life in breast cancer patients (Persian)]. Journal of Shahid Sadoughi University of Medical Sciences. 2008; 16(3):28-36.

[15] Foley E, Baillie A, Huxter M, Price M, Sinclair E. Mindfulness-based cognitive therapy for individuals whose lives have been affected by cancer: A randomized controlled trial. Journal of Consulting and Clinical Psychology. 2010; 78(1):7279. doi: $10.1037 / \mathrm{a} 0017566$

[16] Fasihi Harandi T, Anoosheh M, Ghofranipour F, Montazeri A, Ahmadi F, Mohammadi I, et al. [Health-related quality of life in Iranian breast cancer survivors (Persian)]. Payesh. 2011; 11(1):73-81.

[17] Fadaei S, Janighorban M, Mehrabi T. Study of the effect of cognitive behavioral counseling on body image alterations in woman who have undergone mastectomy. Journal of Research in Medical Sciences. 2011; 16(8):1047-1054. PMCID: PMC3263082

[18] Kissane DW, Clarke DM, Ikin J, Bloch S, Smith GC, Vitetta $\mathrm{L}$, et al. Psychological morbidity and quality of life in Australian women with early stage of breast cancer: A cross sectional survey. Medical Journal of Australia. 1998; 169(4):192-96. PMID: 9734576

[19] Kaviani H, Hatami N, Shafiabadi AS. [Effects of mindfulness-based cognitive therapy for depression on quality of life (non-clinical) (Persian)]. Advances in Cognitive Science. 2008; 10(4):48-39.

[20] Kaviani H, Javaheri F, Bahiraei E. [Effectiveness of Mindfulness-Based Cognitive Therapy (MBCT) in reducing thoughts, dysfunctional attitudes, depression and anxiety (Persian)]. Advances in Cognitive Science. 2005; 7(1):49-59.

[21] Godfrin KA, Van Heeringen C. The effects of mindfulnessbased cognitive therapy on recurrence of depressive episodes, mental health and quality of life. Behaviour Research and Therapy. 2010; 48(8):738-46. doi: 10.1016/j.brat.2010.04.006

[22] Ganz PA, Desmond KA, Leedham B, Rowland JH, Meyerowitz BE, Belin TR. Quality of life in long-term, disease-free survivors of breast cancer: a follow-up study. Journal of the National Cancer Institute. 2002; 94(1):39-49. PMID: 11773281

[23] Hassanpour Dehkordi AS, Shaban M. [Relationship between cancer characteristics and quality of life in the cancer patients under chemotherapy referred to selected clinic of Tehran University of Medical Sciences (Persian)]. Journal of Shahrekord University of Medical Sciences. 2004; 6(4):63-71. 
[24] Harold J, Burstein J, Harris, Monica M. Malignant Tumors of the Breast. In: DeVita VT, Lawrence TS, Rosenberg SA, DePinho RA, Weinberg RA, editors. DeVita, Hellman, and Rosenberg's Cancer: Principles and Practice of Oncology. $9^{\text {th }}$ ed. Philadelphia: Lippincott Williams \& Wilkins; 2011, p. 1401-1445.

[25] Kunkel EJ, Chen EI, Okunlola TB. Psychosocial concerns of women with breast cancer. Primary Care Update Obstetrics \& Gynecology. 2002; 9(4):129-34. doi: 10.1016/s1068607x(02)00103-8

[26] Stewart BW, Kleihues P. World cancer report. Lyon: International Agency for Research on Cancer Press. 2004.

[27] Izadi-Ajirlo A, Bahmani B, Ghanbari-Motlagh A. Effectiveness of cognitive behavioral group intervention on body image improving and increasing self-esteem in women with breast cancer after mastectomy (Persian)]. Journal of Rehabilitation. 2013; 13(4):72-83

[28] Weitzner MA, Meyers CA, Stuebing KK, Saleeba AK. Relationship between mood and quality of life in long-term survivors of breast cancer treated with mastectomy. Journal of Psychosoc Oncolgy. 1997; 5(3):241-48. PMID: 9176972

[29] Knott VE. Psychotherapy and cancer. Adelaide: University of Adelaide; 2006.

[30] Teasdale JD, Segal ZV, Williams JM, Ridgeway VA, Soulsby JM, Lau MA. Prevention of relapse-recurrence in major depression by mindfulness-based cognitive therapy. Journal of Consulting and Clinical Psychology. 2000; 68(4):615-623. PMID: 10965637

[31] Razavi R, Hejazi S, Shahnazarian J, Mahmodi M, Seyyedi SJ. [To compare the patient' body imaging under hemodialysis treatment with patient renal transplantation (Persian)]. Payesh. 2009; 8(3):279-87.

[32] Rahimian AZ. [Health Psychology (Guide to prevention and treatment formulation) (Persian)]. Tehran: Danzheh Publication; 2011.

[33] Sarafino, E. (2010). Health Psychology: Biopsychosocial Interactions. $8^{\text {th }}$ ed. Philadelphia: Wiley \& Sons.

[34] Sammarco A. Perceived social support, uncertainty, and quality of life of younger breast cancer survivors. Cancer Nursing. 2001; 24(3):212-19. doi: 10.1097/00002820200106000-00007

[35] Norouzi, M, Golzari, M, Sohrabi F. Effectiveness of mindfulness based cogni-tive therapy on the quality of life, depression and burden of Alzheimer's wom-en caregivers. Zahedan Journal of Research Medical Science. 2012; 16(9):5-11.

[36] Polizzi TN. An examination of mindfulness-based cognitive therapy for anger drivers [Doctoral dissertation]. New York: Hofstra University; 2007.

[37] Phillips D. Quality of life: Concept, policy and practice. London: Rutledge; 2006.

[38] Sadok BJ, Sadok VA. Kaplan and Sadock's synopsis of psychiatry: behavioral sciences/clinical psychiatry. 10th ed. Philadelphia: Lippincott Williams \& Wilkins; 2007.

[39] Williams JM, Teasdale JD, Segal ZV, Soulsby J. Mindfulness-based cognitive therapy reduces over general autobiographical memory in for merely depressed patients.
Journal of Abnormal Psychology. 2000; 109(1):150-155. doi: 10.1037/ / 0021-843x.109.1.150

[40] Taylor KL, Lamdan RM, Siegel JE, Shelby R, Moran-Klimi K, Hrywna M. Psychological adjustment among African American breast cancer patients: One-year follow-up results of a randomized psychoeducational group intervention. Health Psychology. 2003; 22(3):310-323. doi: 10.1037/02786133.22.3.316

[41] Teasdwle JD. Valve to metacognition [A. Z. Rahimian, Persian trans]. Tehran: Danzheh Publication; 2008.

[42] Uzun O. Quality of life in woman with breast cancer in Turkey. Journal of Nursing Scholarship. 2004; 36(3):207-31. doi: 10.1111/j.1547-5069.2004.04039.x

[43] Segal ZV, Williams JM, Teasdale JD. Mindfulness-based cognitive therapy for depression: A new approach to preventing relapse. $1^{\text {st }}$ ed. New York: Guilford Press; 2001.

[44] Stafford L, Foley E, Judd F, Gibson P, Kiropoulos L, Couper J. Mindfulness-Based Cognitive Therapy (MBCT) for women with gynecologic and breast cancer. Journal of Supportive Care in Cancer. 2013; 21(11):3009-019. doi: 10.1007/s00520013-1880-x

[45] Shimozuma K, Ganz PA, Petersen L, Hirji K. Quality of life in the first year after breast cancer surgery: Rehabilitation needs and patterns of recovery. Breast Cancer Research and Treatment. 1999; 56(1):45-57. doi: 10.1023/a:1006214830854

[46] Lalouei A, Kashani-Zadeh N. Rate of woman's awareness about self breast examination in najmieh and baqiyatollah hospitalsreferrers (Persian)]. Journal of Rehabilitation. 2006; 7(2):66-69

[47] Grant M, Ferrell B, Schmidt GM, Fonbuena P, Niland JC, Forman SJ. Measurement of quality of life in bone marrow transplantation survivors. Quality of Life Research. 1992; 1(6):375-84. doi: 10.1007/bf00704432

[48] Rowland JH, Dioso J, Holland JC, Chaglassian T, Kinne D. Breast Reconstruction after Mastectomy. Plastic and Reconstructive Surgery. 1995; 95(5):812-22. doi: 10.1097/00006534199595050-00007

[49] Hoffman CJ, Ersser SJ, Hopkinson JB, Nicholls PG, Harrington JE, Thomas PW. Effectiveness of mindfulness-based stress reduction in mood, breast- and endocrine-related quality of life, and well-being in stage 0 to III breast cancer: A randomized, controlled trial. Journal of Clinical Oncology. 2012; 30(12):1335-42. doi: 10.1200/jco.2010.34.0331

[50] Witek-Janusek L, Albuquerque K, Chroniak KR, Chroniak C, Durazo-Arvizu R, Mathews HL. Effect of mindfulness based stress reduction on immune function, quality of life and coping in women newly diagnosed with early stage breast cancer. Brain, Behavior, and Immunity. 2008; 22(6):969-81. doi: 10.1016/j.bbi.2008.01.012

[51] Polizzi, TN. An Examination of Mindfulness-based cognitive therapy for Anger Drivers [PhD thesis]. New York: Hofstra University; 2007.

[52] Davoodi, R. Validation of the SF-36 health survey questionnaire in Iranian samples. Journal of Daneshvar Raftar. 2002; 1:1-11. 
